Article

\title{
Prevention of Secondary Lymphedema after Complete Lymph Node Dissection in Melanoma Patients: The Role of Preventive Multiple Lymphatic-Venous Anastomosis in Observational Era
}

\author{
Eleonora Nacchiero ${ }^{1}{ }^{*}$, Michele Maruccia ${ }^{1}$, Fabio Robusto ${ }^{2}$, Rossella Elia ${ }^{1}$, Alessio De Cosmo ${ }^{1}$ \\ and Giuseppe Giudice ${ }^{1}$
}

check for

updates

Citation: Nacchiero, E.; Maruccia, M.; Robusto, F.; Elia, R.; De Cosmo, A.; Giudice, G. Prevention of Secondary Lymphedema after Complete Lymph Node Dissection in Melanoma Patients: The Role of Preventive Multiple Lymphatic-Venous Anastomosis in Observational Era. Medicina 2022, 58, 117. https:// doi.org/10.3390/medicina58010117

Academic Editor: Paola Savoia

Received: 30 November 2021

Accepted: 8 January 2022

Published: 13 January 2022

Publisher's Note: MDPI stays neutral with regard to jurisdictional claims in published maps and institutional affiliations.

Copyright: (C) 2022 by the authors. Licensee MDPI, Basel, Switzerland. This article is an open access article distributed under the terms and conditions of the Creative Commons Attribution (CC BY) license (https:// creativecommons.org/licenses/by/ $4.0 /)$.
1 Department of Plastic Reconstructive and Aesthetic Surgery, Università degli Studi di Bari, 70121 Bari, Italy; marucciam@gmail.com (M.M.); rossellaelia4@gmail.com (R.E.); alessiodicosmo@gmail.com (A.D.C.); giuseppe.giudice@uniba.it (G.G.)

2 Medonline-Statte, Asl Ta, 74010 Statte, TA, Italy; fabiorobusto@libero.it

* Correspondence: eleonora.nacchiero@yahoo.it

\begin{abstract}
Background and Objectives: Current guidelines have limited the performance of complete lymph node dissection (CLND) for patients with clinically detectable lymphatic metastases. Despite the limitations of this surgical procedure, secondary lymphedema (SL) is an unsolved problem that affects approximately $20 \%$ of patients undergoing CLND. Preventive lymphatic-venous microanastomoses (PMLVA) has already demonstrated its efficacy in the prevention of SL in melanoma patients with a positive sentinel lymph node biopsy (SLNB), but the efficacy of this procedure is not demonstrated in patients with clinically detectable lymphatic metastases. Materials and Methods: This retrospective cohort study, was performed in two observation periods. Until March 2018, CLND was proposed to all subjects with positive-SLNB andPMLVA was performed in a subgroup of patients with risk factors for SL (Group 1). From April 2018, according to the modification of melanoma guidelines, all patients with detectable metastatic lymph nodes underwent PMLVA during CLND (Group 2). The frequency of lymphedema in subjects undergoing PMLVA was compared with the control group. Results: Database evaluation revealed 172 patients with melanoma of the trunk with follow-up information for at least 6 mounts. Twenty-three patients underwent PMLVA during CLND until March 2018, 29 from April 2018, and 120 subjects underwent CLND without any preventive surgery (control Group). The frequency of SL was significantly lower in both Group 1 (4.3\% vs. 24.2\%, $p=0.03)$ and Group $2(3.5 \%, p=0.01)$. Patients undergoing PMLVA showed a similar recurrence-free periods and overall survival when compared to the control group. Conclusions: PMLVA significantly reduces the frequency of SL both in immediate and delayed CLND. This procedure is safe and does not lead to an increase in length of hospitalization.
\end{abstract}

Keywords: secondary lymphedema; multiple lymphatic venous anastomosis; melanoma; complete lymph node dissection; observational era

\section{Introduction}

The incidence of melanoma is constantly increasing across the developed countries, while its survival rates have greatly improved over the last three decades. Currently, the overall 5-year survival rate is $90 \%$ in melanoma patients, ranging from 40 to $78 \%$ in patients with lymphatic involvement [1]. Sentinel lymph node biopsy (SLNB) is an indispensable procedure in the staging of melanoma [2], but the benefit of this procedure regarding survival is not unequivocal [3]. Complete lymph node dissection (CLND) for patients with positive sentinel lymph nodes (PSLNs) was the standard of care until very recently [4]; at present, recent trials have testified the absence of any impact on survival for immediate CLND, advising periodic follow-up with an ultrasound of the PSLN basin $[5,6]$. Although CLND does not present a relevant systemic toxicity [7], this surgical procedure is 
no longer recommended in all patients with positive-SLNs because of the risk of acute and chronic local complications [8-10]. To date, CLND is only indicated in the case of isolated locoregional, clinically detectable lymphatic metastases [4].

Lymphedema is the most frequent complication related to CLND at long-term followup, affecting up to $20 \%$ of patients [11]. Chronic lymphedema is associated with esthetical and functional concerns, and could lead to several complications, such as erysipelas, warts, and papillomatosis cutis lymphostatica [12]. Long-term improvements in lymphedema symptoms are rarely achieved despite the use of surgical or physiotherapeutic therapy. Previous studies have testified the effectiveness of preventive multiple lymphatic-venous anastomosis (PMLVA) during CLND in the prevention of secondary lymphedema (SL) [13]. As melanoma guidelines have been modified, recommending that CLND is only performed in subjects with a clinically detectable lymphatic metastasis, melanoma patients undergoing CLND frequently report a more extensive lymphatic involvement. In this setting, namely, in case of more invasive surgery, the efficacy of PMLVAs in the prevention of SL has not been investigated to date.

\section{Methods}

From a single institution digital database, we identified all patients affected by CM of the trunk who underwent SLNB in the axilla or groin from July 1994 to March 2021. The exclusion criteria are as follows: the presence of stage IV melanoma or other carcinomas; compromised lymphatic drainage secondary to prior procedures. All patients underwent lymphoscintigraphy; technetium-nanocolloid human serum albumin was injected close to the primary lesion. The reduction in artefacts was ensured by the use of ultra-highresolution collimators $[14,15]$. Dual-headed digital gamma cameras were used to acquire dynamic and static images after the radiolabeled colloid injection, and then after every node was visualized [16]. Specimens from multiple sections were stained with conventional hematoxylin/eosin and immunohistochemical analysis was performed for each SLN.

SLNB was performed in the case of melanoma with thickness $\geq 0.75 \mathrm{~mm}$ or in case of adverse prognostic features [17]. Until March 2018, CLND was suggested to all patients with positive SLNB; later, this surgical procedure was indicated only in the case of clinically detectable lymphatic metastases, as suggested by new guidelines. Complete therapeutic lymph node dissection involved the three lymphatic levels in the axilla while, in the groin, this included the iliac and obturator lymph nodes [18]. PMLVAs were performed during CLND in a subgroup of patients undergoing lymphadenectomy before March 2018 and in all patients at risk for SL thereafter. The following risk factors for the development of lymphedema were considered: (i) previous radiotherapy, (ii) complicated surgical wounds or seroma, (iii) obesity, (iv) infections, (v) chronic inflammatory cutaneous disorders, (vi)vascular hypertension, (vii) congenital predisposition, (viii) traumatism, (ix) chronic kidney disease, cardiac failure, and malnutrition, (x) arteriovenous shunts, pacemaker, implants, (xi) orthopedic surgery, (xii) venous insufficiency or postphlebitic syndrome, thrombophlebitis, (xiii) familiar anamnesis for chronic edema, and (xiv) hyperthyroidism.

Patent Blue Violet was injected intradermically and at a deep level to prepare for PMA; a " $\mathrm{T}$ " shape was then incised into the skin. PMAs were preferably performed under the same surgical access as CLND; when this was not feasible, a new incision was made at the middle third of the involved limb. Under a microscope magnification of $25 \times$, lymphatic vessels were identified by Patent Blue Violet dye staining and isolated. After the identification and isolation of a vein with sufficient flow, its distal portion was ligated while its proximal portion was clamped. A Nylon 11/0 was used to transfix lymphatic vessels and suture them to the vein through end-to-end telescopic anastomosis with a "Donati" stitch. At this point, single stitches were affixed between the lymphatic and the vein wall. Finally, the first stich and the clamp were removed.

All patients were followed-up in an outpatient setting at 6-month intervals for the first 5 years, and then once a year. They were asked to perform a chest $X$-ray, and abdominal and lymphatic ultrasound. SPECT/CT was indicated for difficult areas. During each follow-up 
visit, we measured calf and bicep circumference and water volumetry [19]. The criteria to define lymphedema were: (1) an increase of $7 \%$ or more in the sum of circumferences of the defined points along the limb; (2) an increase of $15 \%$ or more of the whole limb volume [20,21]. Moreover, body mass index (BMI) was registered during each follow-up visit. A BMI value up to 30 was used as criteria to define obesity and was considered a risk factor for developing lymphedema.

In Group 1, we included the patients who underwent PMLVAs during CLND before April 2018, while patients in whom this preventive technique was used later were included in Group 2. The difference between these groups consisted in the indication of CLND:

- $\quad$ Group 1: Patients underwent CLND in any case of report of positive-SLNB;

- Group 2: Patients underwent CLND only in the case of clinical detectable lymphatic metastasis.

All subjects in whom no preventive surgical technique was performed were included in the control group.

We received approval from the ethics committee of our institution for the implementation of this research protocol (approval code 5029, approval date 18 October 2017). Written informed consent was obtained from all the patients before the surgical procedure. Statistical analysis was performed with $t$-test, Chi-square, and Wilcoxon rank sum test as appropriate. Follow-up time was defined as the time between definitive surgical treatment of the primary melanoma and last contact with the patient. Patients with less than 3 months of follow-up were excluded from the study. Survival rates were estimated using the Kaplan-Meier method and multivariate Cox proportional hazards regression models. $p$ values $<0.05$ were considered statistically significant. All statistical analyses were performed using SAS Software Release 9.4 (SAS Institute, Cary, NC, USA).

\section{Results}

Overall, CLND was performed in 172 patients with melanoma of the trunk and a minimum follow-up of 6 mounts. One-hundred-and-forty-three underwent lymphadenectomy before March 2018 in case of positive SLNB. PMLVA was performed in the same surgical time as CLND in 23 subjects (Group 1), while, in the remaining 120 patients, no preventive surgery was adopted (control group). Otherwise, in accordance with the application of the new guidelines from April 2018, CLND was indicated in 29 subjects and performed only in the case of isolated, locoregional, clinically detectable lymphatic metastases (Group 2). Groups were homogeneous for age, sex, BMI, primary tumor ulceration, mitotic rate, and Breslow thickness (Table 1).

Table 1. Characteristics of subjects that underwent CLND.

\begin{tabular}{|c|c|c|c|c|}
\hline Characteristics & Control Group & Group 1 & Group 2 & $p$ \\
\hline Total, n (\%) & 120 & 23 & 29 & / \\
\hline Gender (M), n (\%) & $64(53.3)$ & $12(52.2)$ & $14(48.3)$ & 0.89 \\
\hline \multicolumn{5}{|l|}{ Age (y) } \\
\hline Median & 53.3 & 54.8 & 54.2 & \multirow{2}{*}{0.43} \\
\hline Range & $18.9-74.2$ & $18.0-68.9$ & $19.8-81.1$ & \\
\hline \multicolumn{5}{|l|}{ Breslow thickness, n (\%) } \\
\hline$<1 \mathrm{~mm}$ & $24(20.0)$ & $5(21.7)$ & $5(17.2)$ & \multirow{4}{*}{0.99} \\
\hline $1-2 \mathrm{~mm}$ & $53(44.2)$ & $10(43.5)$ & $11(37.9)$ & \\
\hline $2-4 \mathrm{~mm}$ & $26(21.7)$ & $5(21.7)$ & $8(27.6)$ & \\
\hline$>4 \mathrm{~mm}$ & $17(14.2)$ & $3(13.0)$ & $5(17.2)$ & \\
\hline Ulceration, n (\%) & $27(22.5)$ & $5(21.7)$ & $8(27.6)$ & 0.83 \\
\hline$>1$ mitosis $/ \mathrm{mm}, \mathrm{n}(\%)$ & $17(14.2)$ & $5(21.7)$ & $7(24.1)$ & 0.35 \\
\hline
\end{tabular}


Table 1. Cont.

\begin{tabular}{ccccc}
\hline Characteristics & Control Group & Group 1 & Group 2 & $p$ \\
\hline Obesity $\left(\mathrm{BMI}>30 \mathrm{~kg} / \mathrm{m}^{2}\right)$ & $16(13.3)$ & $5(21.7)$ & $6(20.7)$ & 0.43 \\
\hline Duration of surgical procedure (hours) & & & & \\
\hline Median & 0.50 & 1.75 & 2.00 & \multirow{2}{*}{$<0.01$} \\
\hline Range & $0.25-1.00$ & $0.50-2.50$ & $0.75-2.75$ & \\
\hline Length of stay (days) & & & & \\
\hline Median & 10 & 10 & 10 & 0.90
\end{tabular}

Additional non-sentinel lymph nodes were detected in $32(26.7 \%)$ subjects in the control group, in 7 (30.4\%) subjects in Group 1 and in 7 subjects in Group $2(p=0.88)$. During follow-up, 55 (45.8\%) deaths were recorded in the control group, in $9(39.1 \%)$ subjects in Group 1 and in $10(34.5 \%)$ subjects in Group $2(p=0.50)$, while, 67 (55.8\%) patients in the control group, 11 (47.8\%) in Group 1, and $14(48.3 \%)$ in Group 2 developed recurrences. No significant differences in both overall survival (log-rank $p=0.72$ ) and disease-free period (log-rank $p=0.69$ ) were detected among the three groups using KaplanMeier analysis at 3 years of follow-up (Figures 1 and 2).

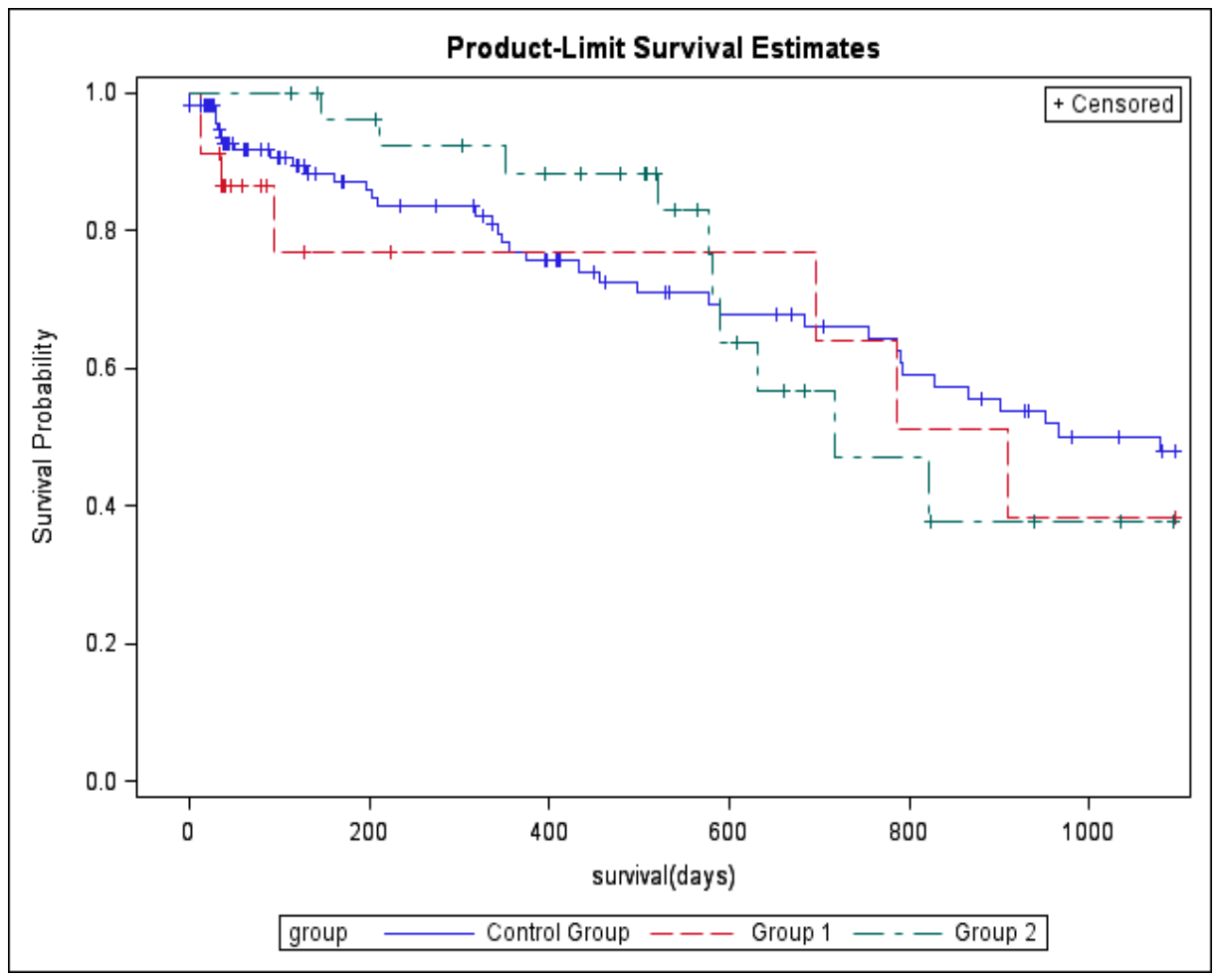

Figure 1. Kaplan-Meier curves for the cumulative risk of death at 3 years.

Overall, SL was detected in 31 of 172 (18.0\%) subjects undergoing CLND. Upper-limb lymphedema after axillary dissection is less frequent than lower-limb lymphedema after groin dissection $(10.0 \%$ vs. $23.5 \%$, Chi-square $p=0.02)$. Considering body mass index (BMI), we detected 31 (18.0\%) obese subjects; there was an insignificantly $(p=0.09)$ higher frequency of obesity among subjects who developed lymphedema (29.6\%) than in the rest of the population $(15.8 \%)$. The use of PMLVA led to a significant reduction in secondary lymphedema in both Group $1(p=0.03)$ and in Group $2(p=0.01)$ when compared with subjects included in the control group. In fact, frequency of SL was $24.2 \%$ (29 of 120 subjects) in the control group, 4.3\% (1 of 23) in Group 1, and 3.5\% (1 of 29) in Group 2. PMLVA 
did not appear to be differently beneficial for the axillary or inguinal district (Table 2). A multivariate logistic regression was conducted to study the risk factors for the development of lymphedema (age, sex, obesity, basin site, and execution of PMLVA). PMLVA resulted an independent protective factor for SL in both Group 1 (OR 0.123, 95\% CI 0.015-0.980, $p<0.05$ ) and Group 2 (OR 0.319, 95\% CI 0.114-0.890, $p<0.05$ ) (Table 3).

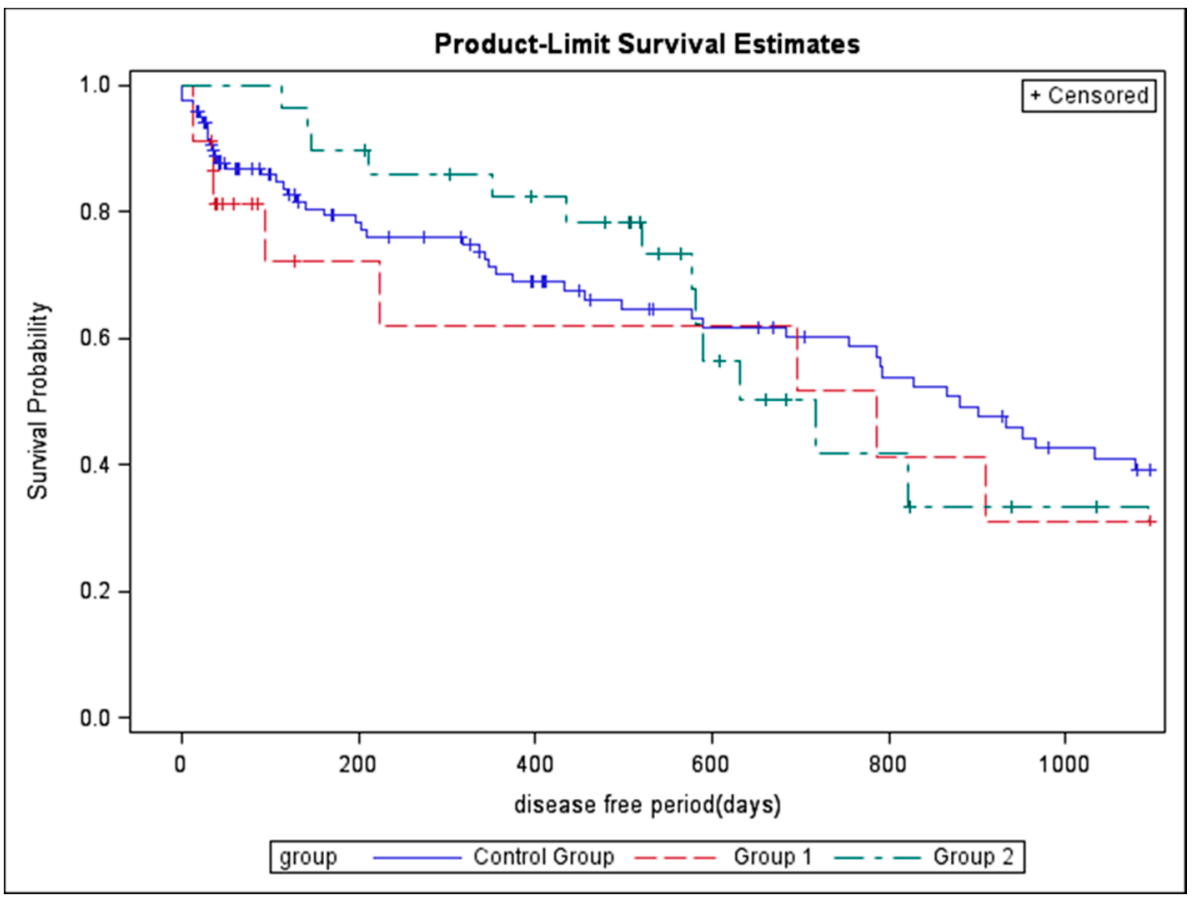

Figure 2. Kaplan-Meier curves for the cumulative risk of recurrence at 3 years.

Table 2. Frequency of lymphedema. Comparison with the results of group 1, group 2 and the control group.

\begin{tabular}{cccccc}
\hline \multirow{2}{*}{ CLND Site } & Control Group & \multicolumn{2}{c}{ Group 1 } & \multicolumn{2}{c}{ Group 2 } \\
\cline { 2 - 6 } & $N$ & $N$ & $p$ & $N$ & $p$ \\
\hline Axilla & $7 / 51(13.7 \%)$ & $0 / 8(0.0 \%)$ & $/$ & $0 / 11(0.0 \%)$ & $/$ \\
\hline Groin & $22 / 69(31.9 \%)$ & $1 / 15(7.7 \%)$ & 0.05 & $1 / 18(5.6 \%)$ & 0.02 \\
\hline TOT & $29 / 120(24.2 \%)$ & $1 / 23(4.3 \%)$ & 0.03 & $1 / 29(3.5 \%)$ & 0.01 \\
\hline
\end{tabular}

Table 3. Multivariate Cox proportional hazards regression models. Comparison among the groups.

\begin{tabular}{|c|c|c|c|c|}
\hline \multirow{2}{*}{ Characteristics } & \multicolumn{2}{|c|}{ Group 1} & \multicolumn{2}{|c|}{ Group 2} \\
\hline & HR & $95 \%$ CI & HR & $95 \% \mathrm{CI}$ \\
\hline \multirow{2}{*}{ Age } & \multirow{2}{*}{1.001} & 0.982 & \multirow{2}{*}{1.006} & 0.989 \\
\hline & & 1.019 & & 1.013 \\
\hline \multirow{2}{*}{$\operatorname{Sex}(\mathrm{M})$} & \multirow{2}{*}{1.503} & 0.603 & \multirow{2}{*}{1.180} & 0.477 \\
\hline & & 3.743 & & 2.919 \\
\hline \multirow{2}{*}{ Obesity } & \multirow{2}{*}{1.738} & 0.588 & \multirow{2}{*}{2.028} & 0.673 \\
\hline & & 5.138 & & 6.115 \\
\hline \multirow{2}{*}{ Lymphatic Basin (groin) } & \multirow{2}{*}{2.542} & 0.952 & \multirow{2}{*}{2.796} & 1.051 \\
\hline & & 6.787 & & 7.440 \\
\hline \multirow{2}{*}{ PMLVA } & \multirow{2}{*}{0.123} & 0.015 & \multirow{2}{*}{0.319} & 0.114 \\
\hline & & 0.980 & & 0.890 \\
\hline
\end{tabular}


The performance of PMLVA significantly increased the surgical time; in fact, the mean duration of surgical procedure in Group 1 and Group 2 was $1.70 \pm 1.49 \mathrm{~h}$ and $1.69 \pm 0.56 \mathrm{~h}$, respectively; this was significantly higher when compared to the $0.51 \pm 0.17 \mathrm{~h}$ of the control group $(p<0.001)$. This significantly longer operating time between subjects undergoing PMLVA and controls was confirmed in both axillary CLNB and groin CLNB. In fact, axillary dissections required a mean time of $0.55 \pm 0.21 \mathrm{~h}$ in the control group, $1.61 \pm 0.48 \mathrm{~h}$ in Group 1, and $1.82 \pm 0.57 \mathrm{~h}$ in Group 2, while the mean duration for groin dissection was $0.49 \pm 0.14 \mathrm{~h}$ in the control group, $1.73 \pm 0.51 \mathrm{~h}$ in Group 1 and $1.61 \pm 0.56 \mathrm{~h}$ in Group 2. On the contrary, the mean length of stay appeared to be similar among the groups: $10.32 \pm 1.12$ days in the control group, $10.36 \pm 1.56$ days in Group 1 and $10.00 \pm 1.81$ days in Group $2(p=0.90)$.

\section{Discussion}

CLND is reserved for melanoma patients with clinically detectable lymphatic metastases, reducing the number of subjects that undergo lymphatic dissection. In prophylactic era, there was a high frequency of CLND in patients with no metastatic lymph nodes. If, on the one hand, the modifications to CLND indications led to a reduction in the number of patients exposed to complications without an improvement in prognosis [7], then currently, patients in whom lymphatic dissections were performed presented a more advanced stage of lymphatic disease. Moreover, the need to perform as exhaustive a CLND as possible was reaffirmed by the adoption of a number of excised lymph nodes as a quality assurance measure for CLND [22]. Regrettably, the execution of more radical CLND led to an increased frequency of local complications, particularly lymphedema [23]. Our report shows an SL frequency of up to $20 \%$ of melanoma subjects undergoing CLND, mimicking the findings reported in recent studies [24]. Over the years, many surgical approaches have been proposed to reduce the risk of SL, including minimally invasive laparoscopic surgery or lymph node transfers [25-37]. Furthermore, compressions or massages are usually used to limit or prevent secondary lymphedema in post-operative rehabilitation [38].

The efficacy of PMLVA was already testified for the prevention of secondary lymphedema after CLND of the axilla or groin in oncologic patients [39]. Moreover, our previous study - whose data have been included in the current article-have demonstrated the efficacy of PMLVA in reducing the risk of SL in melanoma patients exposed to CLND; however, this analysis included all patients with a positive SLNB.

The present analysis has testified the efficacy of the execution of PMLVA during node dissection in reducing the risk of SL in patients who underwent delayed CLND after a clinical evidence of nodal metastasis; therefore, there is a more advanced metastatic involvement of the lymphatic basin than was seen in the previous cohort.

The results of the current study have testified a similar improvement in the prevention of SL in both Group 1 (patients undergoing CLND after a positive SLNB) and Group 2 (patients with clinically detectable lymphatic metastases) with respect to the control group. The efficacy of PMLVA in the reduction in the incidence of SL has been demonstrated even when the results were corrected by other risk factors in a multivariate analysis. This evidence suggests the utility of PMLVA in the prevention of SL, as well as in the case of more advanced lymphatic metastasis, requiring a more invasive surgery.

Moreover, our data have identified that the execution of PMLVA did not impact the prognosis of melanoma patients; in fact, overall-survival and recurrence-free period were similar among groups. Another point in favor of PMLVA is the absence of differences in length of stay among the groups. On the contrary, an increased duration of surgery was reported in patients undergoing PMLVA. Although, on the one hand, the increased surgical time could require more staff and increased instrumental resources, on the other hand, the proven effectiveness of PMLVA in preventing SL could generate cost savings for surgical or physiotherapeutic interventions to treat SL. Thus, the benefits of PMLVA involve lower direct and indirect costs related to SL. 


\section{Conclusions}

This report has demonstrated the efficacy of PLMVA in the prevention of secondary lymphedema in melanoma patients in the observational era, as well as testifying to its effectiveness in subjects with clinical detectable metastasis and a more advanced lymphatic involvement. This surgical technique was safe and had no impact on the length of hospitalization. PMLVA could also be used for the prevention of SL after SLNB; in fact, although this procedure is less commonly associated with $\mathrm{SL}$, the literature reports an incidence of almost $2 \%$ in melanoma patients [40].

Author Contributions: Conceptualization, M.M. and E.N.; methodology, E.N. and M.M.; software, F.R. and E.N.; Validation, A.D.C. and R.E.; Formal Analysis F.R.; Investigation, G.G. and R.E.; data curation, E.N. and A.D.C.; writing - original draft preparation, E.N. and R.E. All authors have read and agreed to the published version of the manuscript.

Funding: All authors hereby declare not to have received funding for this work. This research received no external funding.

Institutional Review Board Statement: "The study was conducted in accordance with the Declaration of Helsinki, and approved by the Institutional Review Board (or Ethics Committee) of Policlinico di Bari (protocol code 5029, approval date 18 October 2017)." for studies involving humans.

Informed Consent Statement: Informed consent was obtained from all subjects involved in the study.

Data Availability Statement: The data presented in this study are available on request from the corresponding author. The data are not publicly available due to privacy and ethical reasons.

Acknowledgments: We thank the staff of Department of Plastic Reconstructive and Aesthetic Surgery of Policlinico di Bari for the cooperation, general interest, and provision of data.

Conflicts of Interest: The authors declare no conflict of interest.

\section{References}

1. Dummer, R.; Hauschild, A.; Lindenblatt, N.; Pentheroudakis, G.; Keilholz, U. Cutaneous melanoma: ESMO Clinical Practice Guidelines for diagnosis, treatment and follow-up. Ann. Oncol. 2015, 26, v126-v132. [CrossRef] [PubMed]

2. Keung, E.Z.; Gershenwald, J.E. The eighth edition American Joint Committee on Cancer (AJCC) melanoma staging system: Implications for melanoma treatment and care. Expert Rev. Anticancer Ther. 2018, 18, 775-784. [CrossRef] [PubMed]

3. Morton, D.L.; Thompson, J.F.; Cochran, A.J.; Mozzillo, N.; Nieweg, O.E.; Roses, D.F.; Hoekstra, H.J.; Karakousis, C.P.; Puleo, C.A.; Coventry, B.J.; et al. Final trial report of sentinel-node biopsy versus nodal observation in melanoma. N. Engl. J. Med. 2014, 370, 599-609. [CrossRef]

4. Michielin, O.; Van Akkooi, A.C.J;; Ascierto, P.A.; Dummer, R.; Keilholz, U.; ESMO Guidelines Committee. Cutaneous melanoma: ESMO Clinical Practice Guidelines for diagnosis, treatment and follow-up. Ann. Oncol. 2019, 30, 1884-1901. [CrossRef]

5. Leiter, U.; Stadler, R.; Mauch, C.; Hohenberger, W.; Brockmeyer, N.; Berking, C.; Sunderkötter, C.; Kaatz, M.; Schulte, K.W.; Lehmann, P.; et al. Complete lymph node dissection versus no dissection in patients with sentinel lymph node biopsy positive melanoma (DeCOG-SLT): A multicentre, randomised, phase 3 trial. Lancet Oncol. 2016, 17, 757-767. [CrossRef]

6. Faries, M.B.; Thompson, J.F.; Cochran, A.J.; Andtbacka, R.H.; Mozzillo, N.; Zager, J.S.; Jahkola, T.; Bowles, T.L.; Testori, A.; Beitsch, P.D.; et al. Completion dissection or observation for sentinel-node metastasis in melanoma. N. Engl. J. Med. 2017, 376, 2211-2222. [CrossRef]

7. Ingvar, C.; Erichsen, C.; Jönsson, P.-E. Morbidity following Prophylactic and Therapeutic Lymph Node Dissection for MelanomaA Comparison. Tumori J. 1984, 70, 529-533. [CrossRef]

8. Madu, M.F.; Franke, V.; Bruin, M.M.; Berger, D.M.; Bierman, C.; Jóźwiak, K.; Klop, W.M.; Wouters, M.W.; van Akkooi, A.C.; Van de Wiel, B.A. Immediate completion lymph node dissection in stage IIIA melanoma does not provide significant additional staging information beyond EORTC SN tumour burden criteria. Eur. J. Cancer 2017, 87, 212-215. [CrossRef]

9. Verver, D.; van Klaveren, D.; van Akkooi, A.C.J.; Rutkowski, P.; Powell, B.W.E.M.; Robert, C.; Testori, A.; van Leeuwen, B.L.; van der Veldt, A.A.M.; Keilholz, U.; et al. Risk stratification of sentinel node-positive melanoma patients defines surgical management and adjuvant therapy treatment considerations. Eur. J Cancer. 2018, 96, 25-33. [CrossRef]

10. de Vries, M.; Hoekstra, H.J.; Hoekstra-Weebers, J.E. Quality of Life After Axillary or Groin Sentinel Lymph Node Biopsy, With or Without Completion Lymph Node Dissection, in Patients With Cutaneous Melanoma. Ann. Surg. Oncol. 2009, 16, $2840-2847$. [CrossRef]

11. Faries, M.B.; The MSLT Cooperative Group; Thompson, J.F.; Cochran, A.; Elashoff, R.; Glass, E.C.; Mozzillo, N.; Nieweg, O.E.; Roses, D.F.; Hoekstra, H.J.; et al. The Impact on Morbidity and Length of Stay of Early Versus Delayed Complete 
Lymphadenectomy in Melanoma: Results of the Multicenter Selective Lymphadenectomy Trial (I). Ann. Surg. Oncol. 2010, 17, 3324-3329. [CrossRef]

12. Giudice, G.; Vestita, M.; Robusto, F.; Annoscia, P.; Ciancio, F.; Nacchiero, E. Breast cancer cutaneous metastases mimicking Papilloma Cutis Lymphostatica. Biopsy to avoid pitfalls. Int. J. Surg. Case Rep. 2018, 46, 31-33. [CrossRef]

13. Nacchiero, E.; Maruccia, M.; Vestita, M.; Elia, R.; Marannino, P.; Giudice, G. Multiple lymphatic-venous anastomoses in reducing the risk of lymphedema in melanoma patients undergoing complete lymph node dissection. A retrospective case-control study. J. Plast. Reconstr. Aesthetic Surg. 2019, 72, 642-648. [CrossRef]

14. Giudice, G.; Robusto, F.; Vestita, M.; Annoscia, P.; Elia, R.; Nacchiero, E. Single-stage excision and sentinel lymph node biopsy in cutaneous melanoma in selected patients: A retrospective case-control study. Melanoma Res. 2017, 27, 573-579. [CrossRef] [PubMed]

15. Nacchiero, E.; Vestita, M.; Robusto, F.; Maruccia, M.; Annoscia, P.; Giudice, G. Surgical management of tumor-positive interval node in melanoma patients. Medicine 2018, 97, e0584. [CrossRef] [PubMed]

16. Chakera, A.H.; Hesse, B.; Burak, Z.; Ballinger, J.R.; Britten, A.; Caracò, C.; Cochran, A.J.; Cook, M.G.; Drzewiecki, K.T.; Essner, R.; et al. EANM-EORTC general recommendations for sentinel node diagnostics in melanoma. Eur. J. Nucl. Med. Mol. Imaging 2009, 36, 1713-1742. [CrossRef]

17. Giudice, G.; Nacchiero, E.; Robusto, F.; Campisi, C. Optimizing the Staging of Melanoma Patients for Their Best Surgical Management. Lymphology 2015, 48, 163-174. [PubMed]

18. Giudice, G.; Robusto, F.; Nacchiero, E. The surgical treatment of a melanoma patient with macroscopic metastasis in peri and retrocaval lymph nodes and with a positive sentinel lymph node in the groin. Ann. Ital. Chir. 2016, 87, S2239253X16024762. [PubMed]

19. Hidding, J.T.; Viehoff, P.; Beurskens, C.H.; Van Laarhoven, H.W.; Der Sanden, M.W.N.-V.; Van Der Wees, P.J. Measurement Properties of Instruments for Measuring of Lymphedema: Systematic Review. Phys. Ther. 2016, 96, 1965-1981. [CrossRef]

20. Starritt, E.C.; Joseph, D.; McKinnon, J.G.; Lo, S.K.; de Wilt, J.H.; Thompson, J.F. Lymphedema after complete axillary node dissection for melanoma: Assessment using a new, objective definition. Ann Surg. 2004, 240, 866-874. [CrossRef]

21. Spillane, A.J.; Saw, R.P.M.; Tucker, M.; Byth, K.; Thompson, J. Defining Lower Limb Lymphedema After Inguinal or Ilio-Inguinal Dissection in Patients With Melanoma Using Classification and Regression Tree Analysis. Ann. Surg. 2008, 248, 286-293. [CrossRef]

22. Rossi, C.R.; Mozzillo, N.; Maurichi, A.; Pasquali, S.; Macripò, G.; Borgognoni, L.; Solari, N.; Piazzalunga, D.; Mascheroni, L.; Giudice, G.; et al. Number of Excised Lymph Nodes as a Quality Assurance Measure for Lymphadenectomy in Melanoma. JAMA Surg. 2014, 149, 700-706. [CrossRef]

23. Sabel, M.S.; Griffith, K.A.; Arora, A.; Shargorodsky, J.; Blazer, D.G.; Rees, R.; Wong, S.L.; Cimmino, V.M.; Chang, A.E. Inguinal node dissection for melanoma in the era of sentinel lymph node biopsy. Surgery 2007, 141, 728-735. [CrossRef]

24. Ciudad, P.; Maruccia, M.; Socas, J.; Lee, M.H.; Chung, K.P.; Constantinescu, T.; Kiranantawat, K.; Nicoli, F.; Sapountzis, S.; Yeo, M.S.; et al. The laparoscopic righ gastroepiploic lymph node flap transfer for upper and lower limb lymphedema: Technique and outcomes. Microsurgery 2017, 37, 197-205. [CrossRef]

25. Lawton, G.; Rasque, H.; Ariyan, S. Preservation of muscle fascia to decrease lymphedema after complete axillary and ilioinguinofemoral lymphadenectomy for melanoma. J. Am. Coll. Surg. 2002, 195, 339-351. [CrossRef]

26. Delman, K.A.; Kooby, D.A.; Ogan, K.; Hsiao, W.; Master, V. Feasibility of a Novel Approach to Inguinal Lymphadenectomy: Minimally Invasive Groin Dissection for Melanoma. Ann. Surg. Oncol. 2009, 17, 731-737. [CrossRef]

27. Cigna, E.; Pierazzi, D.M.; Sereni, S.; Marcasciano, M.; Losco, L.; Bolletta, A. Lymphatico-venous anastomosis in chronic ulcer with venous insufficiency: A case report. Microsurgery 2021, 41, 574-578. [CrossRef] [PubMed]

28. Bolletta, A.; Di Taranto, G.; Chen, S.; Elia, R.; Amorosi, V.; Chan, J.C.; Chen, H. Surgical treatment of Milroy disease. J. Surg. Oncol. 2019, 121, 175-181. [CrossRef] [PubMed]

29. Lo Torto, F.; Kaciulyte, J.; Mori, F.L.; Frattaroli, J.M.; Marcasciano, M.; Casella, D.; Cigna, E.; Losco, L.; Manrique, O.J.; Nicoli, F.; et al. Microsurgical lymphedema treatment: An objective evaluation of the quality of online information. J. Plast. Reconstr. Aesthet. Surg. 2021, 74, 637-640. [CrossRef] [PubMed]

30. Kaciulyte, J.; Garutti, L.; Spadoni, D.; Velazquez-Mujica, J.; Losco, L.; Ciudad, P.; Marcasciano, M.; Torto, F.L.; Casella, D.; Ribuffo, D.; et al. Genital Lymphedema and How to Deal with It: Pearls and Pitfalls from over 38 Years of Experience with Unusual Lymphatic System Impairment. Medicina 2021, 57, 1175. [CrossRef] [PubMed]

31. Di Taranto, G.; Chen, S.H.; Elia, R.; Bolletta, A.; Amorosi, V.; Sitpahul, N.; Chan, J.C.; Ribuffo, D.; Chen, H.C. Free gastroepiploic lymph nodes and omentum flap for treatment of lower limb ulcers in severe lymphedema: Killing two birds with one stone. J. Surg. Oncol. 2020, 121, 168-174. [CrossRef]

32. Di Taranto, G.; Bolletta, A.; Chen, S.H.; Losco, L.; Elia, R.; Cigna, E.; Rubino, C.; Ribuffo, D.; Chen, H.C. A prospective study on combined lymphedema surgery: Gastroepiploic vascularized lymph nodes transfer and lymphaticovenous anastomosis followed by suction lipectomy. Microsurgery 2021, 41, 34-43. [CrossRef]

33. Nacchiero, E.; Maruccia, M.; Elia, R.; Robusto, F.; Giudice, G.; Manrique, O.; Campisi, C. Lymphovenous Anastomosis for the Treatment of Lymphedema: A Systematic Review of the Literature and Meta-Analysis. Lymphology 2020, 53, 172-194. [CrossRef] 
34. Maruccia, M.; Pezzolla, A.; Nacchiero, E.; DiCillo, P.; Macchia, L.; Fiore, P.; Giudice, G.; Elia, R. Efficacy and early results after combining laparoscopic harvest of double gastroepiploic lymph node flap and active physiotherapy for lower extremity lymphedema. Microsurgery 2019, 39, 679-687. [CrossRef] [PubMed]

35. Maruccia, M.; Elia, R.; Ciudad, P.; Nacchiero, E.; Nicoli, F.; Vestita, M.; Chen, H.C.; Giudice, G. Postmastectomy upper limb lymphedema: Combined vascularized lymph node transfer and scar release with fat graft expedites surgical and patients' related outcomes. A retrospective comparative study. J. Plast. Reconstr. Aesthet. Surg. 2019, 72, 892-901. [CrossRef]

36. Ciudad, P.; Manrique, O.J.; Bustos, S.; Coca, J.J.P.; Chang, C.; Shih, P.; Nicoli, F.; Torto, F.L.; Agko, M.; Huang, T.C.; et al. Comparisons in long-term clinical outcomes among patients with upper or lower extremity lymphedema treated with diverse vascularized lymph node transfer. Microsurgery 2019, 40, 130-136. [CrossRef] [PubMed]

37. Baumann, F.T.; Reike, A.; Hallek, M.; Wiskemann, J.; Reimer, V. Does Exercise Have a Preventive Effect on Secondary Lymphedema in Breast Cancer Patients Following Local Treatment-A Systematic Review. Breast Care 2018, 13, 380-385. [CrossRef] [PubMed]

38. Boccardo, F.M.; De Cian, F.; Campisi, C.C.; Molinari, L.; Spinaci, S.; Dessalvi, S.; Talamo, G.; Villa, G.; Bellini, C.; Parodi, A.; et al. Surgical prevention and treatment of lymphedema after lymph node dissection in patients with cutaneous melanoma. Lymphology 2013, 46, 20-26.

39. Hayashida, K.; Yoshida, S.; Yoshimoto, H.; Fujioka, M.; Saijo, H.; Migita, K.; Kumaya, M.; Akita, S. Adipose-Derived Stem Cells and Vascularized Lymph Node Transfers Successfully Treat Mouse Hindlimb Secondary Lymphedema by Early Reconnection of the Lymphatic System and Lymphangiogenesis. Plast. Reconstr. Surg. 2017, 139, 639-651. [CrossRef]

40. Wrone, D.A.; Tanabe, K.K.; Cosimi, A.B.; Gadd, M.A.; Souba, W.W.; Sober, A.J. Lymphedema After Sentinel Lymph Node Biopsy for Cutaneous Melanoma. Arch. Dermatol. 2000, 136, 511-514. [CrossRef] [PubMed] 